\title{
The Impact of Human Resource Management on Organizational Success: Suggestions for Hospitality Educators
}

\author{
Cathy A. Enz \\ Cornell University \\ Mark D. Fulford \\ Cornell University
}

A recent article in the Hospitality and Tourism Educator (Van Hoof, 1991) reported that recruiters for lodging and foodservice organizations consider human resource management (HRM) to be of primary importance when educating hospitality graduate students. The criticality and impact of HRM in the lodging and foodservice industries has been confirmed time and again by recruiters and leaders in the field. And yet, while HRM professionals and corporate leaders publicly acknowledge the importance of HRM, how do operational managers and employees view HRM's role in addressing critical success factors such as increased profitability and enhanced service delivery? Is HRM narrowly confined to the traditional activities of hiring and firing, or is it perceived as having an impact on important strategic issues?

This article reports on a study that examined whether HRM is viewed as having an impact on success factors outside of those traditionally associated with it. Data garnered from a restaurant chain is summarized; however the primary purpose is not to discuss the details of the research, but to consider the implications of the study's findings for hospitality educators. Thus, the primary objective of this paper is to offer suggestions to educators about how to expose future managers to the potential roles HRM can play in operational issues. Before examining what educators can do to enhance student awareness of how to utilize the principles of HRM, we report on what practicing managers believe is the impact of HRM on critical success factors. Curiously, few researchers have explored systematically the question of whether HRM is perceived to have an impact on critical success factors outside the traditional personnel management domains of selection, retention, and payroll administration.

\section{The Study}

We conducted a study on a midwestern restaurant chain to explore the question of whether HRM is perceived to have an impact on organizational success factors. The study was conducted in two stages. In the first stage, we interviewed corporate managers, district supervisors (those who managed restaurant managers within a specific geographic area), and store managers to determine what issues they considered most important for the restaurant chain's success. Interviewees were asked to identify the three issues they deemed most critical 
to the company's success. They also were asked which departments or groups of people are most necessary in dealing with these critical factors. We did not ask questions, however, that specifically examined whether these issues were important HRM issues. These six factorsincreasing profitability; delivering quality, service, cleanliness, and atmosphere; reducing employee turnover; determining customer needs; attracting and retaining employees; and having name recognition and a positive company-were the most frequently mentioned issues believed to be critical to the entire organization's success. They were not attached to any particular functional department or area in the organization.

In the second stage, we surveyed 285 of the restaurant chain's managers and employees in over 50 different restaurant locations to determine their perceptions of the impact of HRM on the six success factors identified in step one. We also examined the opinions of 30 managers at corporate headquarters (excluding those in the training and HRM departments).

The survey asked the managers and employees to indicate the degree to which the HRM department controlled or had an impact on each of the six success factors. The scale ranged from a low of one, indicating that the HRM department did not have an impact on that particular factor, to a high score of seven, indicating that the HRM department was able to completely control that particular factor. A "don't know" option was also provided, and the persons who selected this option were excluded from the study because of their lack of knowledge. This option was important to include so that restaurant operations staff who were not familiar with the HRM department would not give spuriously low ratings on its impact because of their lack of contact with this particular unit.

For the purpose of analysis, we separated the corporate managers' responses from those of the restaurant operations staff (i.e., store managers and crew members). We did this in the belief that the corporate managers may view the role of HRM differently than the operational staff. Their view of HRM may be different because they had more direct contact with the HRM department, which was centrally located at the corporate headquarters.

Table 1 provides a summary of our findings. The bar graphs represent the mean scores for each of the six critical success factors as viewed by the restaurant operations staff and corporate managers. As it suggests, the perceived ability of the HRM department to handle employee turnover and to attract and retain employees was high. These findings were not surprising since these two areas are traditionally associated with personnel departments. In addition, corporate managers viewed the HRM department as more capable of controlling these factors than did those managers and employees in the various restaurant locations.

In contrast, the HRM department was not viewed as having a substantial impact on determining customer needs, increasing profitability, delivering service, quality, cleanliness, or atmosphere, and having name recognition or a positive company image. Regardless of whether restaurant operations staff or corporate managers were surveyed, the pattern of little 
perceived impact persisted. The survey data summarized in Table 1 reveals that both corporate managers and restaurant operations staff narrowly define the impact of the HRM department.

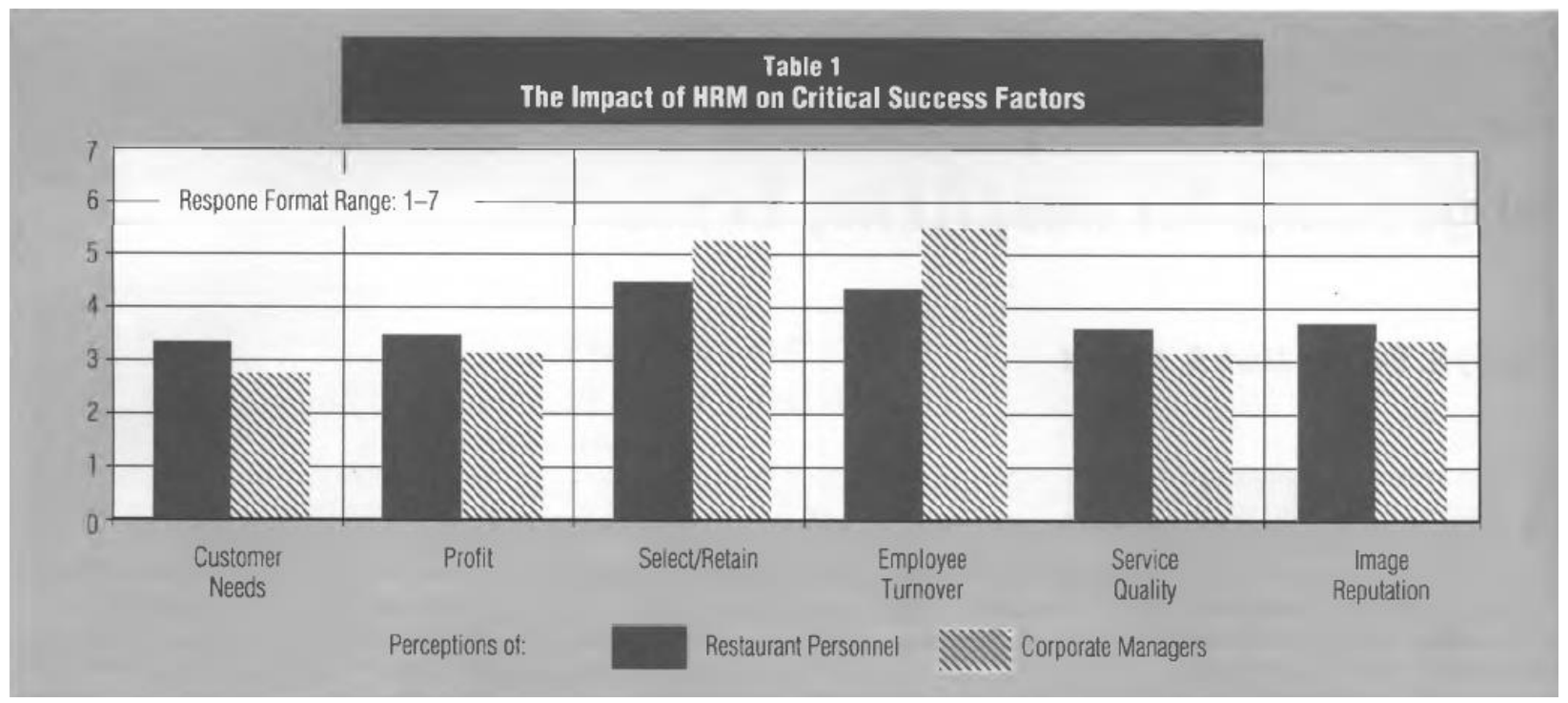

One particularly interesting finding from the survey was that restaurant operations staff viewed the HRM department as having a greater impact on determining customer needs, increasing profitability, delivering service, quality, cleanliness or atmosphere, and having name recognition than did the corporate managers. Restaurant operations staff members were more inclined to perceive the HRM department as influencing issues outside of the traditional boundaries of personnel management than were corporate managers. This finding suggests that a more limited view of the HRM department's role may be held by those at corporate headquarters.

\section{Human Resource Management is Not Personnel Management}

In many cases today, HRM is still known as "personnel." However, the two terms have different meanings. Personnel implies that a narrow functional approach is taken toward a department's activities, while HRM implies an integrative or strategic approach. The differences between the two are more than semantic.

Traditionally, personnel departments were called on to react only after problems were identified. At that, personnel would be used for a short-term "fix." For example, if the company experienced staffing difficulties in a particular department, personnel would simply attempt to hire a few more individuals for that department, without considering the effects such a move would have on the overall operation. On the other hand, HRM dictates a proactive approach, one that anticipates organizational and environmental changes. Such an approach considers the effects of the entire HRM system of management practices on the organization. If used, HRM would be involved in the strategic planning process, and it might avoid staffing difficulties, not by hiring more workers for that department, but by cross-training existing employees in the tasks and responsibilities of the department which is understaffed. HRM also might determine 
the reason for the chronic staffing difficulties of the department, and once discovered, push for an alteration in the selection process or in the compensation package to alleviate the problem. Therefore, unlike personnel, HRM, if used to its full potential, unlike personnel, truly have a major impact on several of the critical success factors. As the data indicate, the restaurant's chain corporate managers did not understand the relevance of HRM practices in influencing these factors.

\section{The Link of HRM to Critical Success Factors}

HRM can have an impact on operations and the bottom line. Just because HRM deals mainly with employee behavior does not mean one cannot transform behavior into economic terms, nor does it that mean the ability to solve a problem, such as employee turnover, does not have a clear linkage to other issues, such as customer service. To believe that HRM can impact employee turnover, for example, but not profitability or service, is to underestimate or misunderstand the connection of employee behavior to organizational effectiveness.

The impact of employee behavior on the bottom line can easily be determined. Let's use employee turnover as an example: It has been estimated that it costs $\$ 2,500$ to replace a hotel worker (Milkovich \& Boudreau, 1991). Looking at, say, a mid-sized property with 200 employees and a 100\% turnover rate, we calculate the annual costs of turnover as follows: 200 employees leaving each year $X \$ 2,500 /$ employee $=\$ 500,000$. Therefore, a $20 \%$ reduction in the turnover rate would mean an annual savings of: $\$ 100,000$ (40 fewer employees leaving each year $X \$ 2,500 /$ employee). Another example is a study that calculated the cost effectiveness of Employee Assistance Programs at two casino hotels (Klebanow \& Eder, 1992). At one property, Klebanow and Eder calculated that $80 \%$ of the total cost of the program was recovered through savings from reduced turnover and absenteeism alone. For a comprehensive discussion of how the economic impact of many employee behaviors and HRM programs can be determined, see Cascio (1991).

Another area in which HRM programs can have a large impact is in providing service, quality, and cleanliness. Quite often, one does not think of HRM as being instrumental in providing customer service, as evidenced by the study's findings reported earlier. However, because of the hospitality industry's labor- intensive nature, customer perception of service, quality, and cleanliness is mainly based on the behavior of employees. HRM, through the design and implementation of effective programs, dictates the behavior employees will be rewarded for exhibiting. For example, if employees are unable to perform certain behaviors that were crucial for providing outstanding customer service, it would be the responsibility of the HRM department to devise a training program to ensure the acquisition of those crucial behaviors. Also, once employees were able to exhibit the crucial behaviors, the HRM department would then need to establish a compensation and reward structure which recognizes employees for providing outstanding service. Employees are more likely to continue exhibiting behavior for which they are rewarded. This would require a revision of the performance appraisal system as well. As one can see, HRM plays a vital role in assuring the delivery of customer service. 
Problems with company image are another area where HRM can have a major impact. If an organization wished to project a certain image through its employees, then the HRM department would need to get involved in a couple of ways. First, it would need to design a selection procedure which would result in the employment of those individuals who fit the organization's "image." Second, the HRM department would need to ensure that, during the orientation phase, employees were informed of the image the organization desired to project and were told that one of the criteria that would be used to evaluate their performance was related to that image. Third, the HRM department would then need to develop a performance appraisal instrument which captured certain elements of the desired image.

In sum, HRM could significantly impact several factors that are considered critical to the success of today's hospitality organizations. Yet, the findings from our study indicate that few managers and employees outside of those who work in a HRM capacity, or those educators who teach HRM, recognize this fact. If one of the objectives of a hospitality management program is to educate students in current management thought, then students need to understand the relevance of HRM practices and theories in resolving critical problems in hospitality operations. Therefore, it is the responsibility of HRM educators in hospitality management programs to engage in the behavior necessary to facilitate such learning by their students.

\section{Suggestions for Hospitality Educators}

Today, HRM involves a more holistic approach versus the narrow orientation of the traditional discipline of personnel. HRM integrates the traditional personnel activities with the operation's strategic objectives in an attempt to ensure the success of the operation.

Therefore, it is paramount that hospitality management students adopt the broader view of HRM. It should be the responsibility of hospitality management educators to provide students with this broader perspective and to ensure they gain an appreciation for its criticality.

How can hospitality educators close the "gap" between the perceptions of HRM and its actual contributions? The following are just a few suggestions:

(1) Evoke the broader applications of HRM. Instead of providing a narrow view to students, educators should discuss the varied contributions that HRM can make in the hospitality industry, in areas such as guest service, company image, profitability, and others.

(2) Convey the importance of HRM. The hospitality educator must stress the importance of the HRM role. For example, one simply needs to point out the labor-intensive nature of the hospitality industry and the effects HRM activities can have on employee behaviors such as performance, absenteeism, turnover, loyalty, grievances, and job-related accidents. Even further, one must point out that it is the employees, not the operation, that engage in the behaviors necessary to provide guests with quality service. 
(3) Integrate HRM throughout the hospitality curriculum. HRM issues should not be limited to management-related courses. Courses in travel and tourism, marketing, and even accounting would benefit from the inclusion of HRM issues. After all, the individuals that perform each of these functions are human resources themselves. It would benefit them to understand the decisions their employers make regarding such things as compensation/ benefits packages, career-development, and employee motivation, to name a few.

(4) Embody the principles of HRM in everyday delivery of courses. Students will gain an appreciation for the value of HRM when its principles are demonstrated and incorporated into the administration of the course. For example, one of the authors teaches a HRM class which involves a weekly recitation section, led by a teaching assistant (TA). In class, performance appraisal issues are discussed and demonstrated. Instead of having students engage in a traditional performance appraisal exercise, in which they evaluate the performance of hypothetical subordinates, they are asked, as a group, to devise a performance appraisal instrument to evaluate the performance of the TA. Each student must then complete the instrument. In this way, students not only learn of the difficulties in identifying effective performance criteria, the subjective nature of evaluating performance, and the amount of time necessary to complete an evaluation, they also digest the "intangibles" involved in the process. Students learn how uncomfortable it can be to evaluate someone when there are consequences involved (rating someone they know versus a hypothetical subordinate), and they believe the rating process is more fair because they actually designed the instrument (versus having one provided for them). This notion of fairness is another issue that needs to be embodied in the conduct of all courses. One of the key components of an effective employee relations program is fair and equitable treatment for all employees. Hospitality educators should treat students in the same fashion. This means for example, that expectations of performance should be communicated to students during the first session and again, frequently, throughout the term. It also means that students are provided with an "appeals mechanism" should they feel a particular component of the course to be unfair, or if they believe inequities exist. Again, this applies to all courses, not just those involving management issues.

\section{Conclusions}

The evidence from our study of a restaurant chain has shown that HRM is perceived to have a limited and narrow impact on the factors critical to success in the foodservice industry. We have attempted to show that HRM can and does have a role to play in influencing success factors such as improved profitability, service quality and positive company image. Finally, we suggest that hospitality educators actively help the managers of tomorrow appreciate all that HRM can contribute to a successful operation. While we agree strongly with recruiters and leaders in the field that HRM is important, it is our hope that the role will be viewed as more integrative and taken more seriously in responding to the critical issues facing the hospitality industry. 


\section{References}

Cascio, W. F. (1991). Costing human resources: The financial impact of behavior in organizations (3rd ed.). Boston: PWS-Kent Publishing Company.

Klebanow, A. M, \& Eder, R. W. (1992). Cost effectiveness of substance-abuse treatment in casino hotels. Cornell Hotel and Restaurant Administration Quarterly, 33, 57-67.

Milkovich, G. I, \& Boudreau, J. W. (1991). Human resource management (6th ed.). Homewood, IL: Richard D. Irwin Publishing Company.

Van Hoof, H. B. (1991). Entering the job market with a master's degree in hospitality management. Hospitality and Tourism Educator, 4, 50-57,73. 